\title{
The Impact of Opinion Leaders on the Consumer Behaviour in the Global Digital Environment
}

\author{
Štefan Žák ${ }^{1, *}$, and Mária Hasprová ${ }^{1}$ \\ ${ }^{1}$ University of Economics in Bratislava, Dolnozemska cesta 1, 852 35, Slovak Republic
}

\begin{abstract}
.
Research background: Opinion leaders have always influenced consumers' decision-making process. At present, with the development of digital technologies and social networks, influencers have taken on the role of opinion leaders worldwide. Influencers represent a very authentic group of people who publish their attitudes, opinions and observations through social media. People sympathize with them because the content they publish is close to them and reminds them of their own lives and the situations they face or would like to experience in the future. The impact of influencers is really great. This is also evidenced by the fact that a separate area called influencer marketing has emerged within the global marketing. Influencer marketing can be defined as the process of researching, identifying, supporting and engaging people in high-impact conversations. Purpose of the article: The aim of the contribution is to point out the history of the activity of opinion leaders in the traditional environment up to the current global digital environment and social networks.

Methods: The authors used the analysis of secondary data and the comparison of knowledge from the results of global research studies and the research study processed by authors.

Findings \& Value added: The article provides a new perspective on the impact of opinion leaders on consumer behaviour and defines the characteristics that are most important in influencing the consumer.
\end{abstract}

Keywords: opinion leaders; consumer behaviour; social networks; global digital environment

JEL Classification: $M 13 ; M 31 ; M 37$

\section{Introduction}

Social networks are places where people meet with a simple intention. That is the purpose of communication. They form circles of their friends or search for groups with common interests. It is social networks that are a suitable place for communities to emerge.

${ }^{*}$ Corresponding author: stefan.zak@euba.sk 
There are a number of social networks. Every year, new ones are created, which try to differentiate themselves in some way, thus trying to attract the largest possible audience. According to their main features, we can divide them into information, professional, educational, hobbies and news. There are also various combinations between them. Users of information social networks are primarily people looking for answers to various questions. In this way, they try to reach individuals or groups who might know the answer. They are also used by companies that try to communicate with the customer, advise him and solve his consumer problems. Professional social networks are designed to help employees or job seekers. Based on the criteria, companies can easily find a suitable candidate for the position they are looking for on these networks. These networks are also created at the corporate level and are used for corporate communication. Educational social networks are used to communicate between schools and students themselves. The reason is communication with students, professors and teachers. They often allow the use of various tools designed for the field of study. Hobby social networks are among the most used and most visited types of social network. Users on these social networks are looking for other people with a similar or similar interest. Or they are simply looking for people they know from everyday life and want to communicate with them online. News social networks form a community of people using this type of social network for sale and obtaining fresh and new information from all over the world. This is the content of websites where members publish newspaper articles, comments, or anything else.

From the very beginning, as social networks began to emerge, companies have sought to find a way to use them effectively for business purposes and to increase the company's reputation. With the growing popularity of social networks, the marketing opportunity has also grown. Due to the growing popularity, it is necessary to constantly look for new ways to change the marketing strategy on the social network [7].

According to the latest data published by We Are Social Inc., we currently have more than 4.54 billion active users online, an increase of $7 \%$ over the last year. Of this number, up to 3.8 billion users use some type of social media. Not surprisingly, these numbers have the potential to grow in the future. Social media offers a myriad of opportunities for entrepreneurial marketing strategies that leverage the power of communities [9]. For companies offering services on the Internet, the time that users spend on social networks is also beneficial. The average user spends 6 hours and 43 minutes a day on the Internet, which is a long enough time for companies to communicate and build a relationship with the customer [13].

Many users operate on social networks and use them with varying intensity. According to the Bednár, users can be divided according to their activity as follows:

- Active users - content creators - belong to the core of social networks. They create content in them by adding statuses, images or other content and form a certain information channel.

- Active users - distributors and evaluators - interact with the content. By such interaction we mean, for example, commenting on posts and creating discussions, sharing and disseminating content, or evaluating a post and review in the form of an opinion.

- Passive users - content evaluators - rating and sharing the contributions of others is their main characteristic. Their most common activity is tagging posts in a form I like. This type of user only reads comments and reviews, but does not add their own comment or opinion.

- Passive users - observing authorities - this type of user is rare. These include authorities who actively engage in discussions with their expert opinions. Such views are rapidly spreading and have a greater impact on the environment, because the authority operates in a given professional field. 
- Passive users - observers - such users have social networks but are not active on them. They only make up consumers with content they don't affect. This type of user is divided into active and passive. An active user group is made up of users who are interested in content but do not interact with it. A passive group of users are referred to as those whose content is not of interest and completely ignored.

With the intensive use of social networks, a new concept of influencer marketing was formed. According to Juraskova and Hornak, "influencer marketing is a form of word-ofmouth marketing based on identifying and influencing opinion leaders who are likely to talk about a product, service or brand, which can influence the opinions of their followers and other consumers [12]."

There are not many definitions of this term, but from the literature dealing with this issue we can conclude that it is primarily about addressing a well-known and influential person, the so-called influencer, which has an impact on a larger number of people. Such a person should be able, through his actions and behaviour, to knowingly or subconsciously influence the shopping behaviour of followers and thus potential customers and consumers. The advantage of such a form of marketing communication is the acquisition of new customers. Research and applied evidence suggest that online opinion leaders are important promoters of products and services in different areas of business and marketing tools [14, 3 , $6,15]$.

According to several sources, influencer marketing is currently one of the most attractive forms of online marketing. It was created by combining new and old marketing tools. The main distinguishing feature among other forms of marketing is that the campaign of individual companies uses cooperation with influential people.

According to Brown and Fiorell, at the core of influencer marketing is a person who has a certain ability to influence others. In everyday life, we could understand the influencer as a parent who shapes the behavior of a child or a designer who determines fashion trends, or a person influencing the religious thinking of religious groups. Influencer marketing has some limitations too, for example cooperating with influencers with high numbers of followers might not be the best marketing choice for promoting divergent products, as this decreases the brand's perceived uniqueness and consequently brand attitudes [5] or consumers could react negatively to influencers' posts when they do not appear with the products they endorse [10].

Until some time ago, for example, university professors and doctors were considered influencers. At present, however, celebrities, bloggers, people known from social media are mostly considered influencers. An inherent part of influencers' success is that they manage to create a personal story that is fun and enjoyable [8].

According to the Cambridge Dictionary, the word influencer is a person who influences or changes the way people behave. It is no different in marketing. We can only find the difference in the goal we want to achieve by influencing. Companies are trying to change shopping behaviour with the help of this form. Thus, to convince the customer to buy the particular product or service, or to prefer the selected brand. Influencer marketing has a great meaning as an effective branding strategy and in their marketing efforts, companies increasingly abandon traditional celebrity endorsers in favour of social media influencers, such as vloggers and instafamous personalities $[11,16]$.

\section{Methodology}

The aim of the contribution is to point out the history of the activity of opinion leaders in the traditional environment up to the current global digital environment and social networks. The article provides a new perspective on the impact of opinion leaders on consumer behaviour and defines the characteristics that are most important in influencing 
the consumer. In order to achieve that objective, we used the basic methods of scientific research - analysis, synthesis, induction, deduction and interrogation. In order to obtain theoretical background to the researched issue, it was based on information available in professional books, magazines and electronic sources from foreign and domestic authors. In this theoretical section we used mainly methods of synthesis and analysis. As part of the marketing research, we applied a quantitative method of inquiry - questioning using an online questionnaire. With the help of the analysis of the obtained data, we were able to break down the individual data on the basis of their importance and relevance. This step has helped us to process data faster and more efficiently. With the help of the use of synthesis, we came to the context that was the subject of this work. We used mathematical-statistical methods to sort and connect individual information, and we commented on and clarified the results using the method of explanation.

\section{Results and discussion}

\subsection{The main results of the survey}

The aim of our survey was to provide a new perspective on the impact of opinion leaders on consumer behaviour and defines the characteristics that are most important in influencing the consumer. We conducted a survey using a standardized questionnaire. The questionnaire consisted of both open and closed questions and was distributed via the Internet. The survey was attended by 360 respondents who were from different age groups and came from different regions. Answers were collected during the May 2020.

Through the questionnaire, we tried to get a number of answers concerning social networks, influencers and their impact and perception by society. In addition to the preference for social networks, we also found out the amount of time that respondents spend on them every day. We investigated whether influencer could really affect consumers' shopping behaviour with the help of a question on trust and a subsequent question in which we asked whether influencer had ever influenced a respondent's purchase. We found that the categories of clothing, cosmetics and electronics had the largest representation. According to these data, we can say that in these categories, the involvement of influencer is effective and advantageous for companies operating in this area.

For the purposes of this article, we chose two key questions from the survey, which concerned the reasons for following influencers and the relationship to influencer advertising posts.

The results concerning the reasons why respondents follow influencers on social networks are interesting. Respondents had to express the degree of agreement with 7 statements, in which we found out how the respondents identify with them.

In the first statement, we tried to find out the importance of the content of posts for followers. The result shows that the content and topic of the post is important for more than $39 \%$ of respondents, only $6 \%$ of respondents stated that they did not agree with this statement. In the second statement, we examined the importance of identifying with the opinion of the influencer. $32.3 \%$ of respondents stated that they fully agree with this statement, another more than $25 \%$ of respondents stated that they rather agree. For only $7.8 \%$ of respondents, the opinion of the influencer is not at all relevant. When saying whether adding beautiful photos and videos has an impact on whether or not respondents will follow influencer, only $6.6 \%$ said that this attribute is not relevant to them at all. More than $35 \%$ said they agreed with the statement and another $28.7 \%$ said they rather agreed with the statement. 
Table 1. The reasons to follow an influencer.

\begin{tabular}{|c|c|c|c|c|c|}
\hline $\begin{array}{c}\text { Why are you following the } \\
\text { influencer? }\end{array}$ & $\begin{array}{c}\text { Strongly } \\
\text { disagree }\end{array}$ & $\begin{array}{c}\text { Rather } \\
\text { disagree }\end{array}$ & $\begin{array}{c}\text { I have no } \\
\text { reserved } \\
\text { opinion }\end{array}$ & $\begin{array}{c}\text { Rather } \\
\text { agree }\end{array}$ & $\begin{array}{c}\text { Strongly } \\
\text { agree }\end{array}$ \\
\hline $\begin{array}{c}\text { I like the content and topic of the } \\
\text { posts he/she adds }\end{array}$ & $6 \%$ & $6 \%$ & $22.3 \%$ & $25.9 \%$ & $39.8 \%$ \\
\hline I like his/her opinion & $7.8 \%$ & $9 \%$ & $25.7 \%$ & $25.1 \%$ & $32.3 \%$ \\
\hline $\begin{array}{c}\text { He/she adds beautiful photos or } \\
\text { videos }\end{array}$ & $6.6 \%$ & $6 \%$ & $23.4 \%$ & $28.7 \%$ & $35.3 \%$ \\
\hline $\begin{array}{c}\text { He/she is close to me in his/her } \\
\text { lifestyle }\end{array}$ & $10.8 \%$ & $18 \%$ & $30.5 \%$ & $24 \%$ & $16.8 \%$ \\
\hline $\begin{array}{c}\text { I want to be informed about trends } \\
\text { in the area I am interested in }\end{array}$ & $6.6 \%$ & $11.4 \%$ & $22.3 \%$ & $28.3 \%$ & $31.3 \%$ \\
\hline $\begin{array}{c}\text { I admire some of his/her features } \\
\text { (talent, physical condition, beauty) }\end{array}$ & $17.5 \%$ & $15.1 \%$ & $16.3 \%$ & $25.3 \%$ & $25.9 \%$ \\
\hline He/she adds original content & $7.8 \%$ & $8.4 \%$ & $18 \%$ & $29.9 \%$ & $35.9 \%$ \\
\hline
\end{tabular}

In the fourth statement, we investigated whether a similar lifestyle with the respondent is the reason for monitoring influencer. The largest part of the respondents $(30.5 \%)$ could not unequivocally confirm or refute whether this is really the case. Awareness through influencer is important for $31.3 \%$ of respondents, $6.6 \%$ of respondents respondents do not attach any importance to information through influencer. In the penultimate statement, we examined the importance of admiration in monitoring influencers. More than $50 \%$ of respondents think that admiration is an important aspect for watching influencer on social media. Almost $33 \%$ of respondents are of the opposite opinion and rather do not attach importance to the influence of influencers in their observation. Finally, we found out the importance of the originality of the influencer. More than $65 \%$ of respondents think that originality is important when choosing an influencer, only $7.8 \%$ of respondents do not attach any importance to the originality of an influencer.

In another series of questions, we surveyed respondents' views on the type of advertising. Participants indicated the extent to which they agreed or disagreed with individual statements. We have summarized their answers in the Table 2.

The first in a series of statements focused on influencers' advertising posts and their impact on consumers. Of all respondents, $18 \%$ think that such posts have no effect on them. The largest group of responses consisted of respondents who were not sure whether or not they were influenced by this form of advertising. In the second statement, we tried to find out whether the consumer considers this form of advertising to be more credible than conventional forms of advertising. In this case, the answers that disagreed with such a statement prevailed, $14 \%$ of respondents do not think at all and another more than $23 \%$ of respondents tend to disagree with this statement. Only $10.5 \%$ of respondents completely agreed with such a statement. The credibility of the influencer is essential in this form of advertising, so we used the third statement to determine whether the number of followers is important for consumer confidence. $22.7 \%$ of respondents strongly disagreed and another $25 \%$ rather disagreed with this statement and are of the opinion that this aspect is not important for trust in influencer. On the contrary, only $8.1 \%$ consider this aspect necessary in connection with trust. 
Table 2. Influencer advertising posts.

\begin{tabular}{|c|c|c|c|c|c|}
\hline $\begin{array}{c}\text { Express your agreement with the } \\
\text { following statements }\end{array}$ & $\begin{array}{c}\text { Strongly } \\
\text { disagree }\end{array}$ & $\begin{array}{c}\text { Rather } \\
\text { disagree }\end{array}$ & $\begin{array}{c}\text { I have } \\
\text { no } \\
\text { reserved } \\
\text { opinion }\end{array}$ & $\begin{array}{c}\text { Rather } \\
\text { agree }\end{array}$ & $\begin{array}{c}\text { Strongly } \\
\text { agree }\end{array}$ \\
\hline $\begin{array}{c}\text { I think that influencers' advertising } \\
\text { posts affect me }\end{array}$ & $18 \%$ & $26.2 \%$ & $27.3 \%$ & $20.9 \%$ & $7.6 \%$ \\
\hline $\begin{array}{c}\text { I consider advertising through } \\
\text { influencers to be more credible than } \\
\text { traditional forms of advertising (TV, } \\
\text { radio, print advertising) }\end{array}$ & $14 \%$ & $23.4 \%$ & $32.2 \%$ & $19.9 \%$ & $10.5 \%$ \\
\hline $\begin{array}{c}\text { I consider influencers with a larger } \\
\text { number of followers to be more } \\
\text { credible }\end{array}$ & $22.7 \%$ & $25 \%$ & $28.5 \%$ & $15.7 \%$ & $8.1 \%$ \\
\hline $\begin{array}{c}\text { The credibility of an influencer } \\
\text { depends on its knowledge of the field } \\
\text { in which it operates }\end{array}$ & $4.6 \%$ & $8.1 \%$ & $23.7 \%$ & $32.4 \%$ & $31.2 \%$ \\
\hline $\begin{array}{c}\text { It bothers me if influencer does not } \\
\text { indicate paid promotion of a product or } \\
\text { service with the appropriate hashtag, } \\
\text { e.g. \#cooperation }\end{array}$ & $25 \%$ & $14 \%$ & $25.6 \%$ & $12.8 \%$ & $22.7 \%$ \\
\hline $\begin{array}{c}\text { When I know it's a paid collaboration, } \\
\text { I trust the review or recommendation } \\
\text { less }\end{array}$ & $11 \%$ & $21.5 \%$ & $36.6 \%$ & $19.2 \%$ & $11.6 \%$ \\
\hline
\end{tabular}

Another statement was also focused on building trust. We asked respondents about linking trust with influencer expertise. In this case, the majority of respondents strongly agreed or rather agreed. Together, these responses accounted for more than $63 \%$, with only $4.6 \%$ of respondents expressing complete disagreement. In the penultimate statement, we asked whether influencer, in the case of paid cooperation, should indicate that it is such cooperation. $39 \%$ of respondents do not mind non-labeling, $22.7 \%$ of respondents bother that influencer does not mark such cooperation. Finally, we found out whether the respondents trust the influencers' paid cooperation less than in the case of unpaid forms of promotion of goods or services. In this case, the opinions were balanced. $11 \%$ did not agree with this statement at all, on the contrary, $11.6 \%$ of the respondents fully agreed.

\subsection{Discussion and recommendations}

We obtained interesting and valuable information from the answers provided by the respondents for the purposes of the research. We focused the most attention on issues focused on shopping behavior and the possible influence of influencers on consumer behavior on the social network. Through an electronic questionnaire, which we sent through social networks, we found out that each respondent uses at least one type of social network, which are an essential part from the point of view of influencer marketing. This information confirmed to us the importance of social networks in online marketing.

The effectiveness of communication on social networks depends on a large number of factors. In order for communication through influencer to be effective, we need to know our customers. Determining the target group is one of the most important factors in choosing a suitable influencer. If a company decides to communicate through influencer marketing, it should be well oriented in the online space and know its possibilities. The importance of the choice lies not only in the selection of a suitable influencer but also in the social network on which he wants to promote the products and services. The right choice will make it possible to address more effectively those customers who could really show interest in the 
company's offer. Due to the high competition and the number of substitute goods, it is necessary to differentiate from the competition.

With the help of an influencer who is knowledgeable in the field and at the same time adds original content, we can more effectively attract potential customers to our side. In order to preserve the naturalness and authenticity of the communication between the influencer and its audience, after agreeing on the terms of the paid cooperation, the company should no longer significantly interfere in this communication. We can constantly monitor whether communication with the help of social networks is really effective with the help of a number of functions.

We also found that influencer marketing, as one of the modern tools, brings new possibilities for online marketing to address customers and communicate with them. In this way, it allows companies to be efficient and communicate with the customer even when he is not in the store. Compared to traditional types of advertising, influencer marketing has the advantage of closer contact with the client, as the customer also spends more time online. Social networks are thus replacing the traditional form of communication. And for this reason, influencer marketing and digital marketing as such have great prospects for the future.

\section{Conclusion}

Influencer marketing is currently having a huge impact that is still growing. An increasing number of companies and brands use it for their marketing. Thanks to increasing banner blindness and also thanks to great consumer confidence in influencers, influencer marketing surpasses current marketing techniques, such as e-mail marketing or various types of PPC advertising. Under the conditions of choosing a suitable influencer, the company is able to effectively attract the target group that the company is interested in. The results of the research confirmed to us that consumers trust more recommendations than traditional forms of advertising. Currently existing as well as potential customers have a large number of products and services to choose from, and a recommendation from influencer can significantly help in their consumer decisions and influence them when buying products. If such a recommendation is from a famous person, it increases the reach of the respondents. The price for this form of advertising depends on the influencer himself. The price is influenced by a number of factors, such as the number of followers, the credibility of the influencer, his expertise in the given issue and many others. Therefore, when selecting a suitable candidate, companies should look for consistency between individual factors so that they use all the allocated funds as efficiently as possible. The authenticity of the influencer and its genuine interest in the promoted product or service result in a greater success rate for such a campaign. In this case, consumers do not see influencer as a common type of advertising, but rather as a friend whom they trust and recommend. Influencer marketing is therefore the right way and tool that helps the company on the one hand not only attract new customers and increase sales, but on the other hand will help in building a good reputation of the company or brand.

This paper is an output of the science project VEGA (S.G.A.) 1/0657/19 The role of influencers in the consumer decision-making process.

\section{References}

1. Bednar, V. (2011). Marketing na sociálních sitích: Prosad'te se na Facebooku a Twitteru. Brno: Computer Press. 
2. Brown, D., Fiorella, S. (2013). Influence marketing: How to create, manage, and measure brand influencers in social media marketing. Indianapols: Que Biz-Tech.

3. Byrne, E., Kearney, J., MacEvilly, C. (2017). The role of influencer marketing and social influencers in public health. Proceedings of the Nutrition Society, 76(OCE3), E103-E103.

4. Cambridge Dictionary. (2020, June 14). Influencer. Retrieved from: https://dictionary.cambridge.org/dictionary/english/influencer.

5. De Veirman, M., Cauberghe, V., Hudders, L. (2017). Marketing through Instagram influencers: The impact of number of followers and product divergence on brand attitude. International Journal of Advertising, 36(5), 798-828.

6. Dhanesh, G. S., Duthler, G. (2019). Relationship management through social media influencers: Effects of followers' awareness of paid endorsement. Public Relations Review, 45(3), 40-52.

7. Ďugová, A. (2016, May 12). Sociálne siete ako marketingový nástroj. Retrieved from: https://www.digitalmag.sk/socialne-siete-ako-marketingovy-nastroj/.

8. Feng, Y., Chen, H., Kong, Q. (2020). An expert with whom i can identify: The role of narratives in influencer marketing. International Journal of Advertising.

9. Fink, M., Koller, M., Gartner, J., Floh A., Harms, R. (2020). Effective entrepreneurial marketing on Facebook - A longitudinal study. Journal of Business Research, 113 (2020), 149-157.

10. Jin, S. V., Muqaddam, A. (2019). Product placement 2.0: Do Brands Need Influencers, or Do Influencers Need Brands? Journal of Brand Management, 26(5), 522-537.

11. Jin, S. V., Muqaddam, A., Ryu, E. (2019). Instafamous and social media influencer marketing. Marketing Intelligence \& Planning, 37(5), 567-579.

12. Juraskova, O., Hornak, P. (2012). Vel'ký slovnik marketingových komunikácí. Praha: Grada Publishing

13. Kemp, S. (2020, January 30). Digital 2020: 3.8 billion people use social media. Retrieved from: https://wearesocial.com/blog/2020/01/digital-2020-3-8-billionpeople-use-social-media.

14. Lin, H. C., Bruning, P. F., Swarna, H. (2018). Using online opinion leaders to promote the hedonic and utilitarian value of products and services. Business Horizons, 61(3), 431-442.

15. Pilgrim, K., Bohnet-Joschko, S. (2019). Selling health and happiness how influencers communicate on Instagram about dieting and exercise: Mixed methods research. Bmc Public Health, 19(1), 9.

16. Schouten, A. P., Janssen, L., Verspaget, M. (2019). Celebrity vs. Influencer endorsements in advertising: the role of identification, credibility, and ProductEndorser fit. International Journal of Advertising, 39(2), 258-281. 